03.1

\title{
Экспериментальное исследование пассивного способа ослабления трансзвукового баффета
}

\author{
(C) М.А. Брутян, А.В. Волков, А.В. Потапчик \\ Центральный аэрогидродинамический институт им. профессора Н.Е. Жуковского, Жуковский, Россия \\ E-mail: m_brut@mail.ru
}

Поступило в Редакцию 20 мая 2019 г.

В окончательной редакции 20 мая 2019г.

Принято к публикации 9 июля 2019г.

\begin{abstract}
Представлены результаты экспериментальных исследований физической картины возникновения явления баффета при трансзвуковых скоростях на модели сверхкритического профиля. Предложен пассивный способ управления этим явлением. связанный с организацией специальных струйных вихрегенераторов. Экспериментально установлено, что предлагаемый подход приводит к задержке возникновения и ослаблению трансзвукового баффета и, как следствие, к улучшению аэродинамических характеристик профиля.
\end{abstract}

Ключевые слова: трансзвуковые течения, экспериментальные исследования, бафтинг, пассивное управление.

DOI: 10.21883/PJTF.2019.21.48467.17881

В случае крейсерского трансзвукового режима полета пассажирских самолетов при числах Маха $\mathrm{M}_{\infty}$, превышающих критическое число Маха $\mathrm{M}_{*}$, на верхней поверхности крыла возникает местная сверхзвуковая зона с замыкающим скачком уплотнения. Когда число $\mathrm{M}_{\infty}$ становится больше некоторого значения $\mathbf{M}_{b u f}\left(\mathbf{M}_{\infty}>\mathbf{M}_{b u f}>\mathbf{M}_{*}\right)$, в диффузорной части крыла за скачком возникает отрыв, который приводит к нестационарному взаимодействию скачка уплотнения с пограничным слоем. Осциллирующее перемещение ударной волны, синхронизированное с отрывом/присоединением пограничного слоя, индуцирует сильное периодическое изменение давления. Этот аэродинамический эффект принято называть баффетом. При взаимодействии с упругой конструкцией крыла колебания такого рода могут привести к негативному явлению бафтинга - сильной тряске, которая отрицательно влияет на самочувствие пассажиров и может из-за усталости конструкции вызвать даже разрушение крыла. Возможность возникновения баффета - аэродинамической составляющей аэроупругого явления бафтинга - следует учитывать при аэродинамическом проектировании, поскольку это явление ограничивает диапазон безопасного полета пассажирских самолетов.

Аэродинамическое совершенство современных пассажирских самолетов постепенно приближается к своему пределу, и борьба идет уже за десятые доли максимального аэродинамического качества. Для заметного прорыва в этой области нужны новые концепции, в основе которых лежат идеи управления обтеканием, активного или пассивного. Поэтому поиск способов управления с целью ослабления трансзвукового баффета является актуальной и важной задачей прикладной аэродинамики. Решение этой задачи открывает новые возможности для улучшения аэродинамических характеристик крыла и летательного аппарата (ЛА) в целом.
Всестороннее изучение бафтинга началось в середине сороковых годов прошлого века, когда благодаря развитию технологий и методов аэродинамического проектирования стал активно осваиваться трансзвуковой диапазон скоростей полета. К настоящему времени как у нас в стране, так и за рубежом выполнено значительное число работ по экспериментальному [1-4] и численному [5-7] исследованию трансзвукового баффета на профилях и крыльях ЛА. Анализ современного состояния этого вопроса можно найти, например, в обзоре [8].

Одним из путей решения проблемы баффета является концепция активного управления посредством тангенциального выдува струи на верхнюю поверхность профиля в области ожидаемого отрыва пограничного слоя. Ранее в ЦАГИ были проведены численные и экспериментальные исследования, которые показали, что данный способ активного управления позволяет улучшить аэродинамические характеристики крыла $[9,10]$.

В настоящей работе представлены результаты экспериментальных исследований нового пассивного способа управления обтеканием, который приводит к задержке возникновения и ослаблению явления баффета. Основное преимущество пассивного способа управления перед активным заключается в том, что его использование не требует дополнительной затраты энергии, которую при активном управлении необходимо получать путем крайне нежелательного отбора от основного компрессора либо от вторичного контура двигательной установки ЛА.

Эксперименты проводились в диапазонах чисел Рейнольдса $\operatorname{Re}=(2.3-2.8) \cdot 10^{6}$ и чисел $\mathrm{M}_{\infty}=0.6-0.8$ в трансзвуковой аэродинамической трубе Т-112 ЦАГИ на модели, выполненной в виде прямоугольного крыла с хордой $200 \mathrm{~mm}$ и размахом $599 \mathrm{~mm}$. Сечение крыла соответствовало геометрии сверхкритического профиля П-184-15 максимальной относительной толщины $15 \%$. 


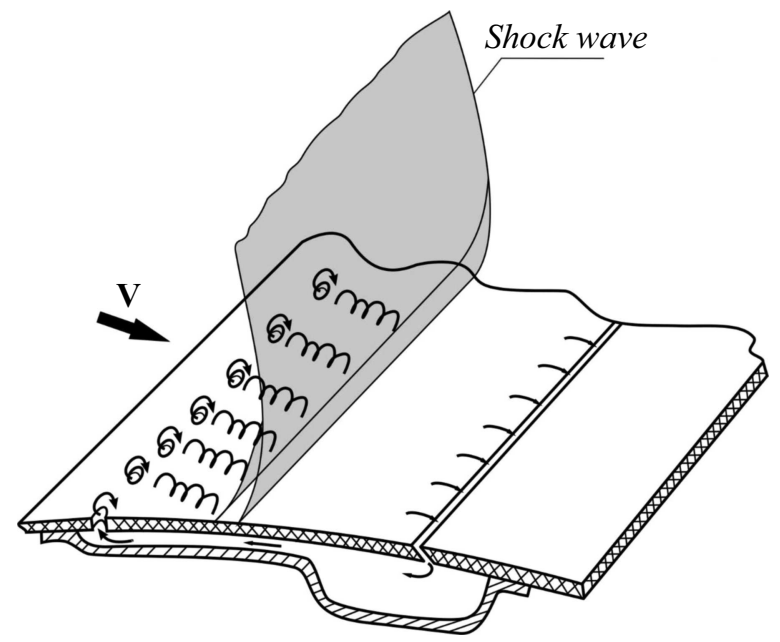

Pис. 1. Принципиальная схема устройства пассивного управления обтеканием с помощью создания воздушных вихрегенераторов.

Верхняя и нижняя стенки рабочей части трубы перфорированы (коэффициент перфорации 23\%). Боковые стенки не перфорированы и имеют оптические окна, между которыми с помощью специальных кронштейнов устанавливается модель, что позволяет проводить оптические исследования картины обтекания одновременно с весовыми измерениями на трехкомпонентных аэродинамических весах. Оптические исследования выполнялись прямотеневым методом с дефокусировкой на расстоянии $460 \mathrm{~mm}$ от торца модели; визуализация картины обтекания модели осуществлялась с использованием импульсной лампы высокой яркости, что дало возможность регистрировать вихревые структуры, возникающие при взаимодействии скачка уплотнения с пограничным слоем.

Как уже отмечалось, основной причиной баффета является колебание скачка, возникающее в определенных условиях при его взаимодействии с пограничным слоем. Для ослабления отрицательного влияния этого взаимодействия предлагается новый способ, основанный на создании струйных вихрегенераторов, располагаемых перед скачком уплотнения и действующих за счет пассивного перепуска воздуха из зоны повышенного давления за скачком уплотнения (рис. 1).

Проверка эффективности нового способа управления обтеканием проводилась на модифицированной модели профиля П-184-15. Модификация состояла в том, что внутри модели была выполнена полость для перепуска воздуха через щель, расположенную на расстоянии 75\% хорды от носка профиля в области за скачком уплотнения. Через эту щель воздух перетекал сначала в полость, а затем из нее попадал к струйным вихрегенераторам, выполненным в виде ряда отверстий на 52\% хорды перед скачком. Отверстия струйных вихрегенераторов диаметром $1 \mathrm{~mm}$ расположены по размаху модели с шагом 3\%. Важно отметить существенную деталь: для получения требуемого эффекта отверстия были выполнены под углом $45^{\circ}$ к поверхности модели в вертикальном сечении, расположенном под углом $\gamma=45^{\circ}$ к направлению потока. В случае поперечного выдува $\left(\gamma=90^{\circ}\right)$ набегающий поток над отверстиями, „натыкаясь“ на струю от вихрегенераторов, притормаживается, что приводит к уменьшению подъемной силы и, как следствие, к негативному влиянию на аэродинамическое качество.

Эксперименты проводились с регистрацией оптической картины обтекания, сопровождаемой скоростной видеорегистрацией и весовыми измерениями аэродинамических характеристик. Результаты исследований модели с управлением (перепуском воздуха) сопоставлялись с результатами испытаний исходной немодифицированной модели без управления. Наиболее полно основные особенности физической картины трансзвукового баффета на модели профиля были изучены при угле атаки $\alpha=4^{\circ}$. Выбор данного угла связан с тем, что, как показали проведенные ранее исследования, при этом угле атаки реализуется значение коэффициента подъемной силы, характерное для крейсерского (наиболее экономичного) режима полета ЛА типа крылатой ракеты.

При докритическом (дозвуковом) обтекании в диапазоне чисел $\mathrm{M}_{\infty}=0.61-0.72$ перепады давления между местами расположения щели и отверстий вихрегенераторов невелики. Поэтому заметного перетекания не происходит, что проявляется на зависимости коэффициента подъемной силы и аэродинамического качества от числа $\mathrm{M}_{\infty}$ (рис. 2). При закритическом (трансзвуковом) режиме обтекания $\left(\mathrm{M}_{\infty}=0.75-0.79\right)$ на верхней поверхности модели без перепуска наблюдается постепенное усиление интенсивности скачка уплотнения и появление $\lambda$-скачка, которое связано с утолщением пограничного

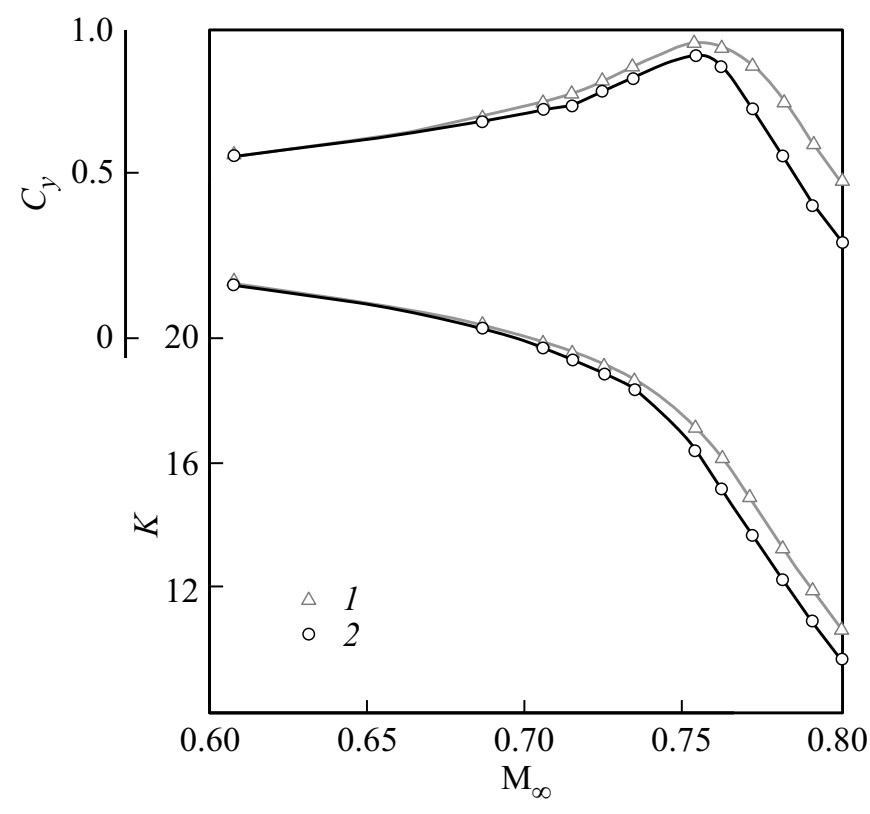

Рис. 2. Экспериментальные зависимости коэффициента подъемной силы и аэродинамического качества от числа Маха набегающего потока. 1 - с управлением, $2-$ без управления. 


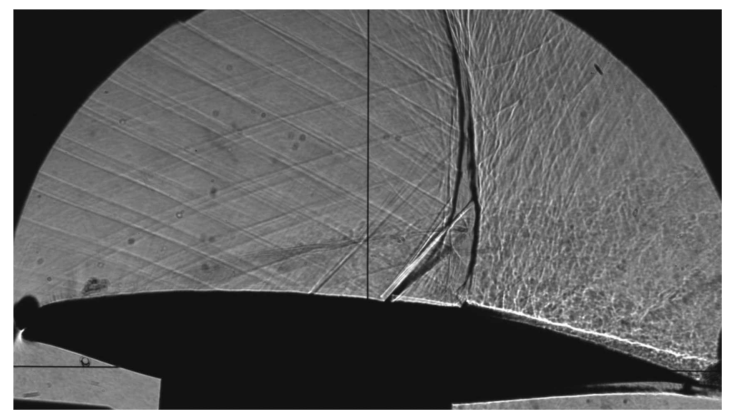

Рис. 3. Оптическая картина обтекания модели профиля со струйными вихрегенераторами. $\mathrm{M}_{\infty}=0.77$.

слоя, не способного преодолеть положительный градиент давления в основном скачке уплотнения.

На оптическом снимке, представленном на рис. 3, можно видеть, что влияние струйных вихрегенераторов приводит к образованию косого скачка уплотнения. Это ведет к уменьшению числа Маха перед основным скачком, что способствует ослаблению его интенсивности. Кроме того, продольные вихри, генерируемые воздушными струями, вызывают перемешивание потока в пограничном слое перед скачком, тем самым затягивая (по числу $\mathrm{M}_{\infty}$ ) момент начала баффета - возникновения отрыва и образования $\lambda$-скачка. Результаты высокоскоростной видеосъемки показали, что при отсутствии $\lambda$-скачка не наблюдается интенсивного вихреобразования, приводящего к заметному увеличению сопротивления и уменьшению аэродинамического качества.

На основании проведенных экспериментальных исследований можно сделать вывод, что струйные вихрегенераторы способствуют перемешиванию нижних низконапорных слоев пограничного слоя с верхними высоконапорными слоями. Это позволяет пограничному слою преодолевать больший перепад давления в области скачка уплотнения без заметного утолщения и образования $\lambda$-скачка. Правильное использование струйных вихрегенераторов приводит к ослаблению явления баффета и улучшению аэродинамических характеристик профиля крыла.

\section{Финансирование работы}

Работа выполнена за счет гранта Российского научного фонда (проект № 16-19-10407).

\section{Конфликт интересов}

Авторы заявляют, что у них нет конфликта интересов.

\section{Список литературы}

[1] Dandois J. // Phys. Fluids. 2016. V. 28. P. 016101. DOI: org/10.1063/1.4937426

[2] Eastwood J.P., Jarrett J.P. // AIAA J. 2012. V. 50. P. 2282 2298. DOI: org/10.2514/1.j051740
[3] Molton P., Dandois J., Lepage A., Brunet V., Bur R. // AIAA J. 2013. V. 51. P. 761-772. DOI: org/10.2514/1.j051000

[4] Gao C.Q., Zhang W.W., Kou J.Q. // J. Fluid. Mech. 2017. V. 824. P. $312-351$. DOI: org/10.17/jfm.2017.344

[5] Gao C.Q., Zhang W.W., Ye Z.Y. // Comput. Fluids. 2016. V. 132. P. 32-45.

[6] Kou J.Q., Le Clainche S., Zhang W.W. // Phys. Fluids. 2018. V. 30. P. 016103.

[7] Zhang W.W., Gao C.Q., Liu Y.L., Ye Z.Y., Jiang Y.W. // Nonlinear Dyn. 2015. V. 82. P. 1851-1865.

[8] Giannelis N.F., Vio G.A., Levinski O. // Prog. Aerosp. Sci. 2017. V. 92. P. 32-84. doi:org/10.1016/j.paerosci

[9] Abramova K.A., Brutyan M.A., Lyapunov S.V., Petrov A.V., Potapchik A.V., Ryzhov A.A., Soudakov V.G. Investigation of buffet control on transonic airfoil by tangential jet blowing // 6th Eur. Conf. for aeronautics and space sciences (EUCASS). Krakov, 2015. P. 1-9.

[10] Boxer V.D., Wolkov A.V., Petrov A.V. // TsAGI Sci. J. 2009. V. 40. P. 9-21. 